05,17

\title{
Магнитные свойства легированных натрием композитов типа фуллерен-терморасширенный графит
}

\author{
(C) В.И. Берёзкин ${ }^{1}$, В.В. Попов ${ }^{2}$, С.В. Кидалов ${ }^{2}$, Н.В. Шаренкова ${ }^{2}$ \\ ${ }^{1}$ Научно-исследовательский центр экологической безопасности РАН, \\ Санкт-Петербург, Россия \\ ${ }^{2}$ Физико-технический институт им. А.Ф. Иофффе РАН, \\ Санкт-Петербург, Россия \\ E-mail: v.berezkin@inbox.ru
}

Поступила в Редакцию 13 мая 2019 г.

В окончательной редакции 13 мая 2019 г.

Принята к публикации 20 мая 2019 г.

Исследованы магнитные свойства (диапазон полей $H=0-50 \mathrm{kOe}$, температур $T=3-300 \mathrm{~K}$ ) и структурные особенности легированного натрием углеродного композиционного материала на основе фуллеренов $\mathrm{C}_{60}$ и терморасширенного графита (ТРГ). Материал при различных соотношениях компонентов получен спеканием при давлении $7 \mathrm{GPa}$ и $T=600^{\circ} \mathrm{C}$, при которых, как оказалось, происходит значительная аморфизация кристаллической решетки исходного $\mathrm{C}_{60}$. Из полного магнитного момента исследованных образцов выделены диа-, пара- и ферромагнитные составляющие части $\left(M_{D}, M_{P M}\right.$ и $\left.M_{F M}\right)$. Влияния примеси натрия на магнитные свойства композита не обнаружено. Анализ полевых зависимостей $M_{P M}(H)$ с помощью функции Бриллюэна для фуллеренового (т.е. без ТРГ) образца позволил определить квантовое число полного момента количества движения парамагнитных (ПМ) центров. Его величина оказалась равной $J=1$, что соответствует элементарному магнитному моменту ПМ центра $\mu_{P M}=2 \mu_{\mathrm{B}}$. Оценки концентрации ПМ центров оказались на уровне $N_{P M} \approx(2-5) \cdot 10^{18} \mathrm{~g}^{-1}$ для большинства образцов, включая материал без ТРГ. Введение в исходный состав ТРГ и увеличение его доли в композите приводит к сильному возрастанию магнитного момента, что объясняется ростом как величины $J$, так и содержания ПМ центров.

Ключевые слова: фуллерены, графит, углеродные композиты, магнитные свойства.

DOI: $10.21883 /$ FTT.2019.10.48251.477

\section{1. Введение}

Магнитные свойства углеродных объектов привлекают особое внимание исследователей в связи с целым рядом обстоятельств. Так, атомы углерода содержат только $s$ - и $p$-электроны. Кристаллические формы углерода алмаз, графит, фуллерит - являются диамагнетиками. В то же время во многих углеродных модификациях наблюдается пара- и ферромагнетизм. В частности, в ряде чисто углеродных структур и некоторых органических веществах без специально введенных магнитных атомов наблюдается ферромагнитный гистерезис, сохраняющийся до высоких температур, вплоть до $T=800 \mathrm{~K}$ [1]. Все это вызывает научный интерес. Открывается также перспектива практических приложений, например, получение неметаллических биосовместимых магнитов.

Наиболее интересные результаты по магнитным свойствам углеродных объектов получены, на наш взгляд, при изучении структур на основе фуллеренов. В подобных системах синтезированы и исследованы вещества с очень широким диапазоном свойств - от идеальных диамагнетиков (то есть сверхпроводников) до ферромагнитно упорядоченных структур.

При спонтанной кристаллизации фуллерены объединяются, как правило, в молекулярную решетку типа гранецентрированный куб (ГЦК). Такой материал, формально являясь полупроводником n-типа (ширина запрещенной зоны находится в диапазоне примерно $1.5-2 \mathrm{eV})$, фактически обладает свойствами диэлектрика, удельное сопротивление которого достигает величины $10^{14} \Omega \cdot \mathrm{cm}[2]$. Интеркалирование щелочными и другими металлами может повышать электропроводность фуллеренов вплоть до металлической, изменять симметрию, трансформируя решетку в другие типы, а также приводить к различным фазовым переходам. Например, интеркалированное соединение $\mathrm{Cs}_{3} \mathrm{C}_{60}$ является антиферромагнитным диэлектриком, который при приложении внешнего давления становится сверхпроводником [3]. Иными словами, происходит фазовый переход диэлектрик-сверхпроводник. Интеркалирование может порождать полимеризованное состояние [4], основа которого - линейные цепочки типа $\mathrm{AC}_{60}(\mathrm{~A}-$ щелочной металл). Наиболее полная полимеризация, вПлоть до частично трехмерной, реализуется в результате воздействия на неинтеркалированные фуллерены высоких давлений и температур (технология НРНТ [5]). В результате исходная молекулярная решетка типа ГЦК при определенных сочетаниях температур, давлений и времен воздействия может трансформироваться в ковалентную (с более высокой электропроводностью) тетрагональную, орторомбическую или ромбоэдрическую решетку. В технологии НРНТ в определенном интервале 
температур и давлений синтеза увеличивается степень беспорядка в расположении молекул, а сами они начинают разрушаться, что сопровождается увеличением твердости материала [6]. При этом в ромбоэдрической полимерной фазе наблюдается также возрастание концентрации магнитных центров [7].

С дальнейшим ростом температуры и давления получаются аморфизированные графитоподобные $\left(s p^{2}\right)$ и алмазоподобные $\left(s p^{3}\right)$ углеродные структуры, вплоть до технических алмазов различных типов, которые, как правило, синтезируют в присутствии металлических примесей-катализаторов (обычно группы железа) [5]. При синтезе по технологии НРНТ алмазов из графита фуллерены используются как сокатализатор фазового перехода графит-алмаз [8].

Экспериментальные данные показывают, что появление в углероде магнитных моментов наблюдается при каких-либо отклонениях от исходной регулярной кристаллической структуры. Теоретически рассмотрены такие причины возникновения нескомпенсированных спинов, как, например, искажения решетки графита, приводящие к появлению сочетаний $s p^{2}$ - и $s p^{3}$ гибридизированных атомов углерода; внедрение примесных немагнитных атомов с разной валентностью; наличие топологических дефектов (например, типа Стоуна-Уэлса) в двумерных гексагональных структурах, дефектов типа атом углерода - вакансия; наличие оборванных связей в неупорядоченных структурах или в объектах с пониженной размерностью и протяженностью. В частности, в таких аллотропных модификациях углерода, как нанотрубки или графены, магнитные моменты могут возникать за счет нескомпенсированных спиновых состояний свободных связей на границах. В целом природа магнитных явлений в углеродных объектах остается пока не выясненной, так что модельнотеоретические представления об их магнитных свойствах развиты явно недостаточно [1].

Дополнительные возможности управлять параметрами углеродных материалов открываются в связи с разработкой композитов, приобретающих новые качества. При варьировании составом и условиями получения можно добиться такой перестройки межмолекулярных и межатомных связей, которая отразится на электрических, магнитных и других свойствах.

Так, в работах $[9,10]$ предложены и исследованы композиционные углерод-углеродные материалы, в которых фуллерены $\mathrm{C}_{60}$ размещаются в углеродной матрице, причем ковалентно связываются с ней. Композиты синтезированы по технологии НРНТ из исходных механических дисперсных смесей, включавших фуллерены, а также разлагающиеся углеводородные связующие вещества и соединения, содержащие различные легирующие элементы. При использовании композиции фуллерены + нафталин + азид натрия при исходном молекулярном соотношении компонентов $1 \mathrm{C}_{60}: 6 \mathrm{C}_{10} \mathrm{H}_{8}: 3.5 \mathrm{NaN}_{3}$ получено сверхпроводящее состояние, причем высокостабильное в воздушной среде, в отличие от хорошо известных интеркалированных фуллеренов-сверхпроводников (см., например, $[3,11]$ ). В [12] представлен и описан другой композиционный материал, нелегированный, где в качестве основы углеродной матрицы, вмещающей фуллерены, использован ТРГ. Здесь при увеличении относительного содержания фуллеренов до определенного порога наблюдается очень резкий перколяционный переход проводникизолятор [13].

В настоящей работе по технологии НРНТ синтезирован легированный натрием композиционный материал системы $\mathrm{C}_{60}-\mathrm{TP \Gamma} \mathrm{при} \mathrm{различных} \mathrm{соотношениях} \mathrm{компо-}$ нентов. В композите в широком диапазоне магнитных полей и температур измерен магнитный момент. Проведен также рентгеноструктурный анализ экспериментальных образцов.

\section{2. Экспериментальные образцы и измерения}

Исходный ТРГ - это, как известно, материал, который получается путем быстрого нагрева интеркалированного неорганическими кислотами тонко смолотого графита, как правило, природного. В результате частицы графита вспучиваются, распадаются на фрагменты, расстояния между атомными слоями в них увеличиваются в сотни раз, так что образуется очень легкая углеродная субстанция с насыпной плотностью, сравнимой с плотностью газов.

Механически перемешанные исходные дисперсные смеси ТРГ и поликристаллических порошков фуллеренов $\mathrm{C}_{60}$ с решеткой типа ГЦК помещались в предварительно отожженные при температуре около $650^{\circ} \mathrm{C}$ стеклянные ампулы, которые откачивались при одновременном подъеме температуры до $200^{\circ} \mathrm{C}$ и отпаивались. Затем они обрабатывались в течение времени до $6 \mathrm{~h}$ при температурах $550-600^{\circ} \mathrm{C}$, что значительно выше температуры сублимации фуллеренов (примерно равной $400^{\circ} \mathrm{C}$ ) и ниже температуры начала разрушения молекул $\mathrm{C}_{60}$ (обычно равной $700-900^{\circ} \mathrm{C}$ ). Так что компоненты дополнительно перемешивались в довольно длительном диффузионно-адсорбционном процессе. Детали данной процедуры и особенности использованного ТРГ описаны в [12].

Для легирования материала использовался азид натрия, $\mathrm{NaN}_{3}$, как и в работах $[9,10]$. Он разлагается на элементарный $\mathrm{Na}$ и азот $\mathrm{N}_{2}$ при температуре $275^{\circ} \mathrm{C}$. К смеси $\mathrm{C}_{60}+$ ТРГ после ее термообработки добавлялся $\mathrm{NaN}_{3}$, все тщательно перемешивалось механически. Новая смесь $\mathrm{C}_{60}+\mathrm{TP} \Gamma+\mathrm{NaN}_{3}$ обрабатывалась по технологии НРНТ при давлении $7 \mathrm{GPa}$ и температуре $600^{\circ} \mathrm{C}$ в условиях квазигидростатического сжатия. Процедура была такой. Сначала поднималось давление, затем в камере высокого давления устанавливалась температура, после чего следовала выдержка $1 \mathrm{~min}$, затем нагрев выключался, давление снималось. 
В итоге получен целый ряд образцов при различных соотношениях $\mathrm{C}_{60}$, ТРГ и $\mathrm{Na}$ в исходных смесях. Были приготовлены составы как аналогичные тем, что использованы в $[9,10]$, так и другие. А именно, в настоящей работе получены образцы при весовых (или атомных, что то же самое в данном случае) соотношениях $\mathrm{C}_{60}$ и ТРГ, равных $\mathrm{C}_{60}:$ ТРГ $=128: 1 ; 64: 1 ; \ldots ; 1: 2$ (образцы №№ 2-9). Количество натрия было таким, чтобы во всех исходных смесях на каждую молекулу $\mathrm{C}_{60}$ приходилось по три атома $\mathrm{Na}$ (или молекулы $\mathrm{NaN}_{3}$ ). Так что, например, при соотношении $\mathrm{C}_{60}:$ ТРГ $=32: 1$ относительное количество атомов $\mathrm{Na}$ (или молекул $\mathrm{NaN}_{3}$ ) в исходном составе было равно $32 \times 3=96$. В качестве образца сравнения при тех же условиях НРНТ-спекания был получен материал с исходным составом $\mathrm{C}_{60}: \mathrm{NaN}_{3}=1: 3$ (по молекулам), обозначенный как № 1.

Измерения магнитного момента в полученных образцах выполнялись вибрационным методом в аппарате PPMS QD в магнитных полях до $H=50 \mathrm{kOe}$ и в диапазоне температур $T=3-300 \mathrm{~K}$. Рентгенодифрактограммы получены на установке ДРОН-2 (излучение $\mathrm{Cu} K_{\alpha}$ ).

\section{3. Результаты и обсуждение}

Состав образцов и ряд их параметров, определенных из экспериментов, приведены в таблице. На рис. 1 показаны температурные зависимости магнитной восприимчивости, $\Delta \chi(T)$, полученные из измеренного в поле $H=1 \mathrm{kOe}$ магнитного момента, $M(T)$, после вычитания диамагнитной составляющей. Видно, что величины $\Delta \chi$ слабо зависят от температуры при ее снижении примерно до $T=50 \mathrm{~K}$, а в области $T<50 \mathrm{~K}$ наблюдается существенный рост положительного вклада в восприимчивость.

На рис. 2 представлены типичные экспериментальные и расчетные полевые зависимости магнитного момента,

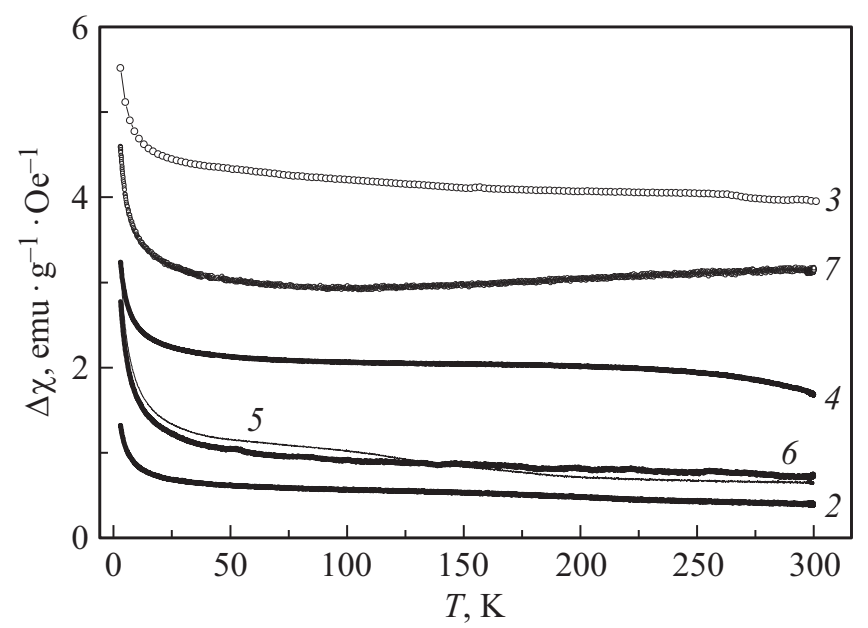

Рис. 1. Зависимость положительной составляющей магнитной восприимчивости ряда образцов от температуры. Номера кривых соответствуют номерам образцов в таблице.

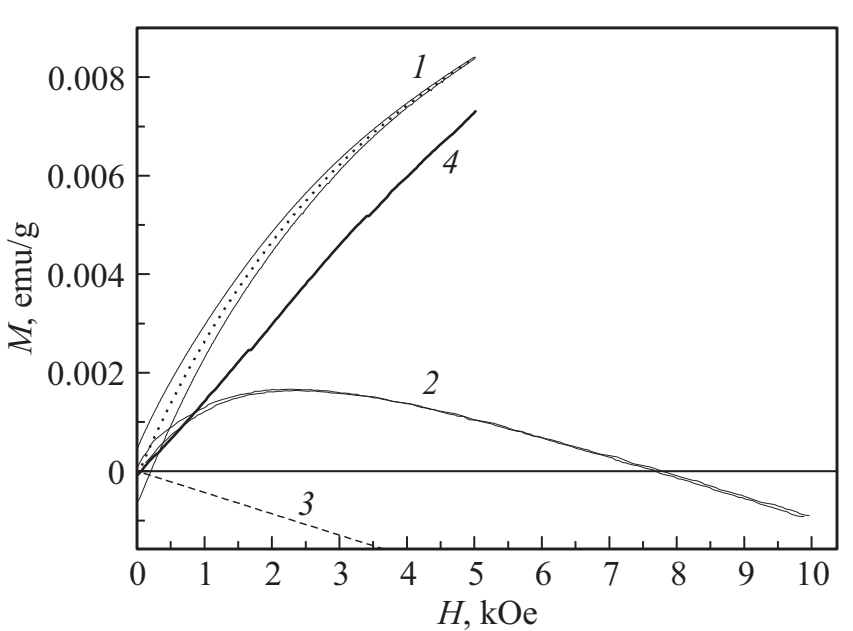

Рис. 2. Зависимости магнитного момента от магнитного поля для образца № 4. Кривая $1-M(H)$, измеренный при $T=3 \mathrm{~K}$ (точками обозначена усредненная, то есть не учитывающая гистерезис, кривая); кривая $2-$ то же при $T=300 \mathrm{~K}$; зависимость 3 - расчетная диамагнитная составляющая момента $M$, то есть $M_{D}$, полученная из кривой 2 ; кривая $4-$ расчетная парамагнитная составляющая момента $M$, то есть $M_{P M}(H)$, полученная из кривой 1 с помощью соотношения (2).

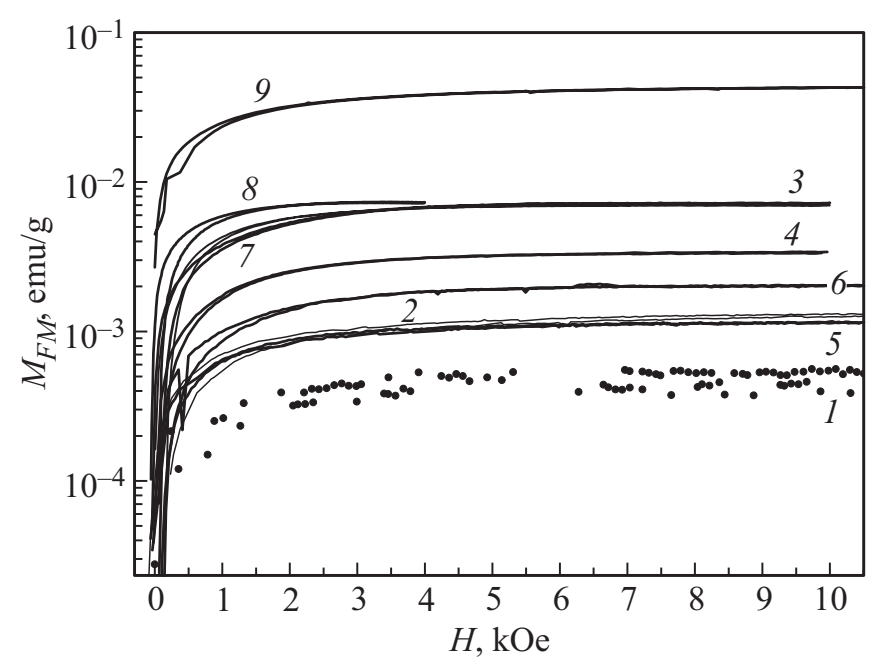

Рис. 3. Ферромагнитные составляющие магнитного момента $M_{F M}(H)$ всех исследованных образцов при $T=300 \mathrm{~K}$.

$M(H)$, на примере образца № 4. Видно, что положительный при $T=3 \mathrm{~K}$ магнитный момент (кривая 1 ) при комнатной температуре (кривая 2) с ростом поля подавляется линейной отрицательной диамагнитной составляющей $M_{D}=-\left|\chi_{D}\right| \cdot H$ (пунктирная линия 3), которую можно определить по наклону зависимости $M(H, T=300 \mathrm{~K})$, т.е. кривой 2 , в сильных магнитных полях (в данном случае при $H>5 \mathrm{kOe}$ ).

Если в интервале $T=50-300 \mathrm{~K}$ из зависимостей $M(H)$ вычесть $M_{D}(H)$, то получатся кривые с насыщением, характерные для ферромагнитного состояния вещества. Такие зависимости, $M_{F M}(H)$, для всех исследованных образцов приведены на рис. 3. 
Исходные составы* и некоторые экспериментально определенные параметры, относящиеся к магнитным свойствам образцов

\begin{tabular}{|c|c|c|c|c|}
\hline $\begin{array}{c}\text { № } \\
\text { образца }\end{array}$ & $\begin{array}{c}\text { Исходное весовое } \\
\text { (атомное) } \\
\text { соотношение } \\
\text { С }_{60}: \text { ТРГ }\end{array}$ & $\begin{array}{c}\text { Диамагнитная } \\
\text { восприимчивость, } \\
-\chi_{D}(T=300 \mathrm{~K}), \\
10^{-4} \mathrm{emu} /(\mathrm{g} \cdot \mathrm{Oe})\end{array}$ & $\begin{array}{c}\text { Ферромагнитный } \\
\text { момент насыщения, } \\
M_{F M_{s}}, 10^{-3} \mathrm{emu} / \mathrm{g} \\
(T=300 \mathrm{~K})\end{array}$ & $\begin{array}{c}\text { Концентрация } \\
\text { парамагнитных } \\
\text { центров, } N_{P M}, \\
10^{18} \mathrm{~g}^{-1}\end{array}$ \\
\hline 1 & $1: 0$ & 2.3 & 0.45 & 5.1 \\
\hline 2 & $128: 1$ & 6.4 & 1.3 & 4.1 \\
\hline 3 & $64: 1$ & 5.0 & 6.9 & 2.3 \\
\hline 4 & $32: 1$ & 4.3 & 3.3 & 2.6 \\
\hline 5 & $24: 1$ & 7.6 & 1.1 & 5.4 \\
\hline 6 & $16: 1$ & 5.9 & 2.2 & 4.9 \\
\hline 7 & $8: 1$ & 5.7 & 7.2 & 3.2 \\
\hline 8 & $1: 1$ & 14 & 7.3 & (4.3) \\
\hline 9 & $1: 2$ & 41 & 44 & (13.8) \\
\hline
\end{tabular}

Примечан ие. * Содержание $\mathrm{Na}$ во всех образцах таково, что в исходных смесях на каждую молекулу $\mathrm{C}_{60}$ приходилось по три атома a.

Как уже отмечалось выше, при низких температурах $(T<50 \mathrm{~K})$ в образцах наблюдается рост величин $\Delta \chi(T)$. Одновременно с этим наблюдается сильный рост магнитного момента при увеличении напряженности магнитного поля, рис. 2, кривая 1. Все это характерно для парамагнитного поведения момента, в нашем случае для парамагнитной составляющей $M_{P M}(H, T=3 \mathrm{~K})$. Таким образом, полный магнитный момент всех образцов можно представить в виде суммы соответствующих вкладов

$$
M=M_{D}+M_{F M}+M_{P M} .
$$

Проведенные нами измерения входящих в соотношение (1) зависимостей $M_{D}(H)$ и $M_{F M}(H)$ в интервале температур $T=50-300 \mathrm{~K}$ показали, что от температуры они практически не зависят. Отсюда следует, что низкотемпературный парамагнитный вклад, $M_{P M}$, можно получить, используя экспериментальные зависимости, измеренные при двух температурах, путем их вычитания следующим образом:

$M_{P M}(H, T=3 \mathrm{~K})=M(H, T=3 \mathrm{~K})-M(H, T=300 \mathrm{~K})$.

Результат для образца № 4 показан на рис. 2, кривая 4 (гистерезис, заметный на экспериментальной кривой 1 , для расчета с помощью соотношения (2) усреднялся). Видно, что зависимость $M_{P M}(H)$ близка к линейной, как и должно быть для парамагнитного поведения момента в слабых полях. Аналогичные зависимости для всех исследованных образцов приведены на рис. 4.

Зависимость магнитного момента парамагнетика от магнитного поля описывается, как хорошо известно, с помощью функции Бриллюэна (ФБ) следующим образом:

$$
\begin{aligned}
& M_{P M}=N_{P M} J g \mu_{\mathrm{B}} \\
& \quad \times\left\{\frac{2 J+1}{2} \operatorname{coth}\left[\frac{(2 J+1) x}{2 J}\right]-\frac{1}{2 J} \operatorname{coth}\left(\frac{x}{2 J}\right)\right\},
\end{aligned}
$$

где собственно ФБ заключена в фигурных скобках; $N_{P M}$ - содержание ПМ центров в $1 \mathrm{~g}$ вещества, $J-$

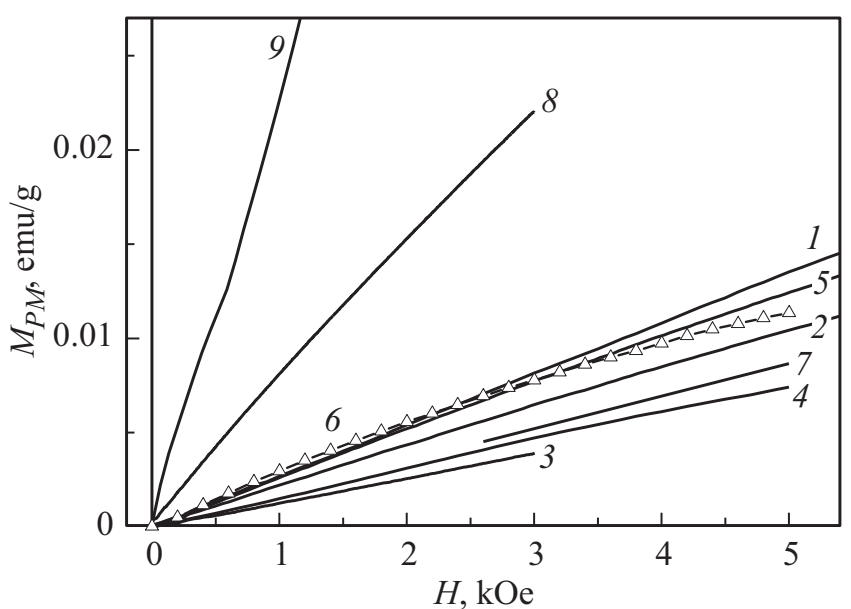

Рис. 4. Зависимость выделенной с помощью уравнения (2) парамагнитной составляющей магнитного момента от магнитного поля при $T=3 \mathrm{~K}$ для всех исследованных образцов.

квантовое число полного момента количества движения; $g-g$-фактор; $\mu_{\mathrm{B}}-$ магнетон Бора; $x=J g \mu_{\mathrm{B}} H / k_{\mathrm{B}} T$; $k_{\mathrm{B}}$ - постоянная Больцмана. При увеличении магнитного поля ФБ стремится к единице, а $M_{P M}$ к насыщению величиной, соответственно, равной $M_{P M_{s}}=N_{P M} J g \mu_{\mathrm{B}}$. Использование соотношения (3) позволяет найти оба неизвестных параметра, $J$ и $N_{P M}$.

На рис. 5 экспериментальными точками показана зависимость $M_{P M}(H)$ при $T=3 \mathrm{~K}$ для образца № 1, определенная с помощью выражения (2) и измеренная в сильных полях до $50 \mathrm{kOe}$, где заметен переход к насыщению. Здесь же сплошной линией показана кривая, рассчитанная по формуле (3) для величин $g=2, J=1$ и $N_{P M}=5.1 \cdot 10^{18} \mathrm{~g}^{-1}$. В образце № 1 , напомним, углеродная составляющая в исходном материале полностью состоит из фуллерена $\mathrm{C}_{60}$. Поэтому в дальнейших расчетах для образцов с превалирующим содержанием $\mathrm{C}_{60}$ принималась величина $J=1$, что соответствует элементарному магнитному моменту ПМ центра $\mu_{P M}=2 \mu_{\mathrm{B}}$. Для 


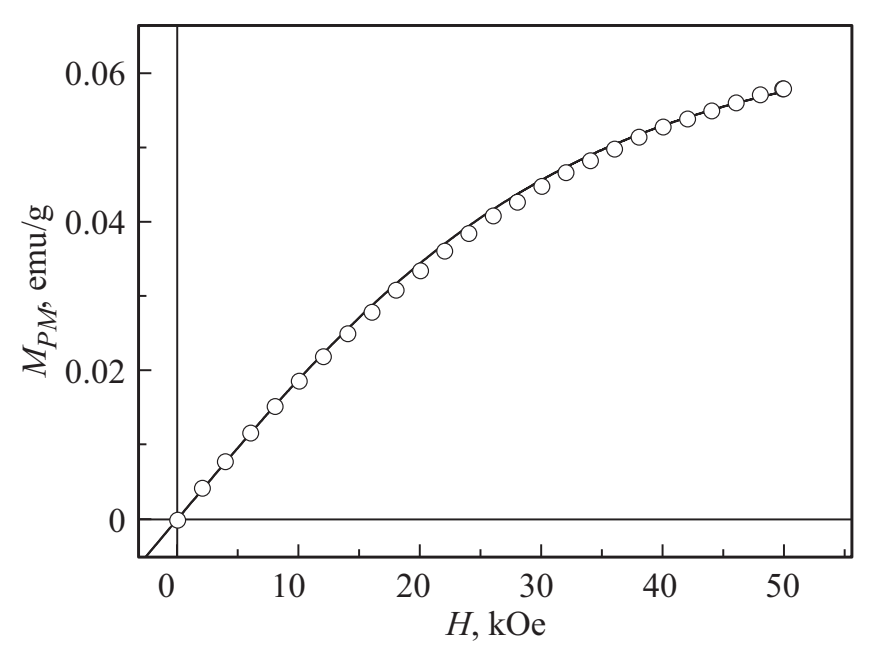

Рис. 5. Зависимость выделенной парамагнитной составляющей магнитного момента от магнитного поля при $T=3 \mathrm{~K}$ для образца № 1 (точки); сплошная линия - расчет по формуле (3) для $J=1$ и $N_{P M}=5.1 \cdot 10^{18} \mathrm{~g}^{-1}$.

анализа зависимостей $M_{P M}(H)$ в остальных образцах, измеренных в более слабых полях (см. рис. 4), можно использовать линейное приближение формулы (3), а именно, выражение

$$
M_{P M}(H)=N_{P M} K_{J} g^{2} \mu_{\mathrm{B}}^{2} H /\left(3 k_{\mathrm{B}} T\right),
$$

где $K_{J}=J(J+1)$ для одного компонента композита.

Полученные с помощью выражений (3) и (4) величины $N_{P M}$ для всех образцов представлены в таблице. Отсюда и из рис. 4 видно, что образцы $1-7$, которые состоят главным образом из фуллеренового компонента, характеризуются близкими по величине и наклону зависимостями $M_{P M}(H)$. В то же время образцы №№ 8 и 9 по указанным параметрам сильно отличаются. Очевидно, это связано с существенным увеличением доли ТРГ в исходных составах. Чтобы из уравнения (3) найти величину $N_{P M}$, необходимо знать величину $J$, связанную с ТРГ, которая зависит от природы парамагнитного центра.

В литературе при исследовании дефектных центров углерода чаще всего встречается значение $J=1 / 2$, что соответствует одному электронному спину $J=S=1 / 2$ и, соответственно, магнитному моменту дефекта $\mu_{P M}=\mu_{\mathrm{B}}$. Такими дефектами оказываются, например, вакансии при облучении графеновых слоев протонами или ионами углерода [14]. В то же время при исследовании дефектов в углеродных структурах встречаются и другие величины $J$. Например, в работе [15] показано, что в графеновых кристаллах, полученных путем расщепленния графита ультразвуком, величина квантового числа $J$ оказалась близкой к значениям $J=2$ или $J=5 / 2$.

Использованный нами исходный ТРГ состоит из частиц графита, расщепленных на слои термически, как уже говорилось выше (соответствующие электронномикроскопические снимки представлены в [12]). Иными словами, использованный ТРГ по своей природе довольно близок к графеновым объектам. Для оценки содержания парамагнитных центров в смешанных образцах № 8 $\left(\mathrm{C}_{60}:\right.$ ТРГ $\left.=1: 1\right)$ и № $9\left(\mathrm{C}_{60}:\right.$ ТРГ $\left.=1: 2\right)$, где доли $\mathrm{C}_{60}$ и ТРГ сравнимы между собой, мы воспользовались формулой (4), в которой для расчета коэффициента $K_{J}=J(J+1)$ учитывался парциальный вклад в общий момент обеих составляющих со значениями $J=1$ для фуллеренового и $J=2$ для ТРГ-компонента. В таблице полученные таким образом суммарные величины $N_{P M}$ для образцов №№ 8 и 9 приведены в скобках. В соответствии с формулой (4) резкое возрастание магнитного момента при увеличении содержания ТРГ, в первую очередь, связано с увеличением в два раза $J$ для ТРГкомпонента. Видно, что для образца № 8 величина $N_{P M}$ получилась почти такая же, как и для образцов №№ 1-7, в то время как величина $M_{P M}(H)$ для этого же образца (кривая 8 , рис. 4) резко возросла. В образце № 9 в увеличение магнитного момента $M_{P M}(H)$ (кривая 9, рис. 4) дает вклад как рост $J$ ТРГ-компонента, так и увеличение общего содержания парамагнитных центров $N_{P M}$. Полученные оценки концентраций ПМ центров в образцах №№ $1-8$, примерно равные $N_{P M} \approx(2-5) \cdot 10^{18} \mathrm{~g}^{-1}$, являются типичными величинами для магнитных дефектных углеродных структур [16,17]. Поскольку такая концентрация в расчете на единицу объема недостаточна для ферромагнитного взаимодействия, то можно предположить, что ПМ центры располагаются компактно в нано- или микрообластях с повышенной концентрацией дефектов. Сравнение величин насыщения ферромагнитного момента, $M_{F M_{s}}$, таблица и рис. 3 , с концентрацией ПМ центров в образцах №№ 1-8 не обнаруживает их взаимной корреляции из-за сильного разброса $M_{F M_{s}}$. Вместе с этим сильное возрастание $N_{P M}$ в образце № 9 приводит и к заметному росту $M_{F M_{s}}$, что указывает на возможно одинаковую природу центров, участвующих в ферромагнитных и парамагнитных эффектах в этом образце.

Что касается роли натрия, то здесь можно сказать следующее. Сам по себе $\mathrm{Na}$, как известно, парамагнитен. Однако в условиях нашей технологии он в образцах, скорее всего, химически связывается с углеродом, и, далее, из-за некоторой возможной пористости материала, с атмосферными газами. Соединения натрия обладают, как правило, слабыми парамагнитными или диамагнитными свойствами, поэтому не должны давать заметного вклада в общий парамагнитный момент. Так что магнитные эффекты, исследованные в данной статье, связаны с углеродными компонентами композитов.

Если говорить о структуре наших образцов, то на рис. 6 в качестве иллюстрации показаны рентгенографические данные для образцов №№ 4 и 6, а также для использованного исходного фуллерена $\mathrm{C}_{60}$ (Pristine Fullerene, PF). Видно, что при указанных выше параметpax спекания (температурах и давлениях) происходит 


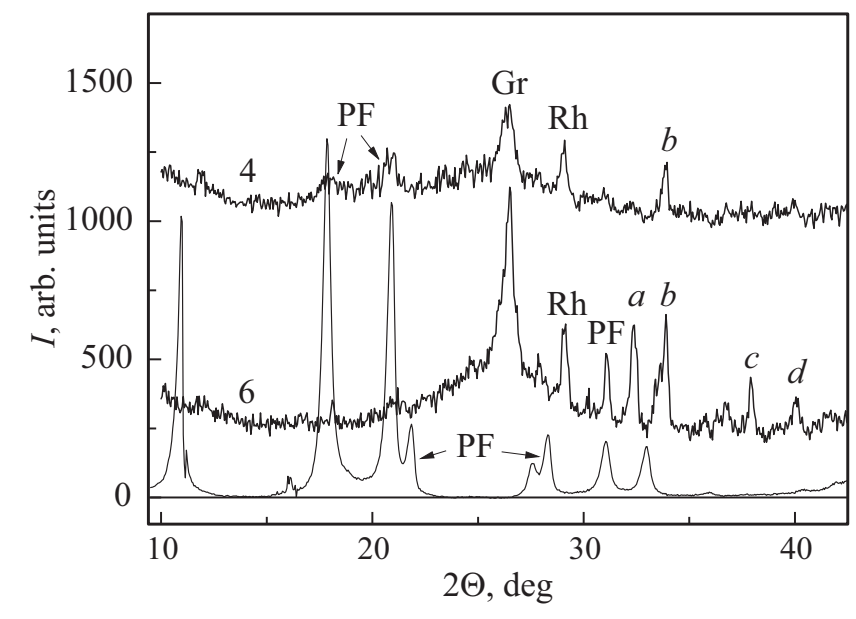

Рис. 6. Рентгенодифрактограммы исходного фуллерена $\mathrm{C}_{60}$, PF (Pristine Fullerene), и образцов № 4 и 6 . Остальные пояснения в тексте.

частичная аморфизация решетки типа ГЦК исходного $\mathrm{C}_{60}-$ увеличивается рентгеноаморфная составляющая углерода, в образцах наблюдаются лишь некоторые пики от PF, причем с резко сниженной амплитудой. Появляется пик $\mathrm{Rh}$, характерный для ромбоэдрической модификации фуллерена. В обоих образцах присутствует особенность Gr, соответствующая рефлексу (002) кристалла графита, которая выглядит так, как это характерно для разупорядоченных графитоподобных фаз. Иными словами можно сказать, что синтезированные образцы характеризуются высокой степенью дефектности по сравнению с исходным $\mathrm{C}_{60}$. Отметим также, что на рис. 6 наблюдаются пики $a, b, c$ и $d$, не связанные ни с фуллереновой, ни с графитовой составляющей частью композита. Эти особенности, вероятно, обусловлены какой-либо другой смешанной или промежуточной углеродной фазой.

\section{4. Заключение}

Методом высоких давлений и температур синтезирован легированный натрием углеродный композит на основе фуллеренов и терморасширенного графита при различных соотношениях компонентов. Экспериментально исследованы его магнитные свойства и структурные особенности.

Анализ рентгенографических данных показал, что при использованных параметрах спекания $\left(7 \mathrm{GPa}\right.$ и $\left.600^{\circ} \mathrm{C}\right)$ происходит значительная аморфизация решетки типа ГЦК исходного $\mathrm{C}_{60}$, появляется его ромбоэдрическая модификации, а также структура, идентифицировать которую не удалось. В образцах присутствует также разупорядоченная графитоподобная фаза и аморфный углерод.

Из полного магнитного момента исследованных образцов выделены диа-, пара- и ферромагнитные состав- ляющие части. Оценки концентрации парамагнитных центров, $N_{P M}$, для большинства образцов, включая материал без ТРГ, оказались на уровне $(2-5) \cdot 10^{18} \mathrm{~g}^{-1}$, что типично для углеродных структур, в которых регистрируемые ПМ центры связаны с дефектами структуры. Влияния примеси натрия на магнитные свойства не обнаружено. Сделан вывод, что магнитные свойства исследованных образцов определяются углеродными компонентами композита.

Анализ полевых зависимостей $M_{P M}(H)$ с помощью функции Бриллюэна для фуллеренового (то есть без ТРГ) образца позволил определить квантовое число полного момента количества движения ПМ центра. Его величина оказалась равной $J=1$, что соответствует элементарному магнитному моменту ПМ центра $\mu_{P M}=2 \mu_{\mathrm{B}}$.

Введение в исходный состав ТРГ и увеличение его доли в композите приводит к сильному возрастанию магнитного момента, что объясняется ростом как величины $J$, так и содержания ПМ центров.

\section{Финансирование работы}

Работа выполнена в рамках государственных тематических исследований ФТИ им. А.Ф. Иоффе по теме „Физико-химические основы технологии новых функциональных материалов на основе углеродных наноструктур“.

\section{Конфликт интересов}

Авторы заявляют, что у них нет конфликта интересов.

\section{Список литературы}

[1] Т.Л. Макарова. ФТП 38, 641 (2004).

[2] Т.Л. Макарова. ФТП 35, 257 (2001).

[3] A.Y. Ganin, Y. Takabayashi, P. Jeglič, D. Arčon, A. Potočnik, P.J. Baker, Y. Ohishi, M.T. McDonald, M.D. Tzirakis, A. McLennan, G.R. Darling, M. Takata, M.J. Rosseinsky, K. Prassides. Nature 466, 221 (2010).

[4] K. Khazeni, J. Hone, N.G. Chopra, A. Zettl, J. Nguyen, R. Jeanloz. Appl. Phys. A 64, 263 (1997).

[5] В.И. Березкин. Углерод: замкнутые наночастицы, макроструктуры, материалы. АРТЭГО, СПб. (2013). 450 с.

[6] R.A. Wood, M.H. Lewis, G. West, S.M. Bennington, M.G. Cain, N. Kitamura. J. Phys.: Condens. Matter. 12, 10411 (2000).

[7] R.A. Wood, M.H. Lewis, M.R. Lees, S.M. Bennington, M.G. Cain, N. Kitamura. J. Phys.: Condens. Matter 14, L385 (2002).

[8] V.M. Davidenko, S.V. Kidalov, F.M. Shakhov, M.A. Yagovkina, V.A. Yashin, A.Ya. Vul'. Diamond Related Mater. 13, 2203 (2004).

[9] В.И. Березкин. Письма в ЖЭТФ 83, 455 (2006).

[10] В.И. Березкин, В.В. Попов. ФТТ 49, 1719 (2007).

[11] V. Buntar, H.W. Weber. Supercond. Sci. Technol. 9, 599 (1996). 
[12] В.И. Березкин, В.В. Попов, М.В. Томкович. ФТТ 59, 601 (2017).

[13] В.И. Березкин, В.В. Попов. ФТТ 60, 202 (2018).

[14] R.R. Nair, M. Sepioni, I-Ling Tsai, O. Lehtinen, J. Keinonen, A.V. Krasheninnikov, T. Thomson, A.K. Geim, I.V. Grigorieva. Nature Phys. 8, 199 (2012).

[15] M. Sepioni, R.R. Nair, S. Rablen, J. Narayanan, F. Tuna, R. Winpenny, A.K. Geim, I.V. Grigorieva. Phys. Rev. Lett. 105, 207205 (2010).

[16] T.L. Makarova, B. Sundqvist, P. Esquinazi, R. Höhne, Y. Kopelevich, P. Scharff, V.A. Davydov, L.S. Kashevarova, A.V. Rakhmanina. Nature 413, 718 (2001).

[17] P. Esquinazi, R. Hohne. J. Magn. Magn. Mater. 290-291, 20 (2005).

Редактор Т.Н. Василевская 